\title{
INTEGRASI NILAI DALAM PEMBELAJARAN BERBASIS MULTIKULTURAL DI SEKOLAH DASAR
}

\author{
Ratih Rahmawati \\ UIN Sunan Kalijaga Yogyakarta \\ Jl. Laksda Adisucipto, Caturtunggal, Kec. Depok, Kabupaten Sleman, \\ Daerah Istimerwa Yogyakarta 55281 \\ e-mail:ratibra7@gmail.com
}

\begin{abstract}
Values covers everything assumed meaningful for someone's life in which its considerations are based on the quality of true-false, good-bad, or beautiful-unbeautiful and its orientation is anthropocentric or theocentric. The scope of values taught in formal education is indeed large; therefore the process of realizing the values can run integrally in the educational process. The educational attempts in term of intra-curricular, extracurricular or school's cultural atmosphere is a place where the values can be integrally implemented in the educational process. The value education is very good to be implanted since the early ages as the prevention of value conflict due to differences in identity, gender, ethnicity, race, and culture. Therefore, value education through multicultural learning should be intensified and as the main subject is elementary school students. With this they are expected to be ready to live in harmony peace and harmony.
\end{abstract}

Keywords: value education, multicultural, elementary school

\begin{abstract}
Abstrak
Nilai mencakup segala sesuatu yang dianggap bermakna bagi kehidupan seseorang yang pertimbangannya didasarkan pada kualitas benar-salah, baik-buruk, atau indab-tidak indah, dan orientasinya bersifat antroposentris atau theosentris. Ruang lingkup nilai yang diajarkan dalam pendidikan formal demikian luas, maka proses penyadaran nilai-nilai dapat berlangsung secara integral dalam proses pendidikan. Tindakan-tindakan pendidikan dalam lingkup intrakulikuler, ekstrakulikuler, maupun iklim budaya sekolah merupakan ruang tempat pendidikan nilai itu berlangsung. Pendidikan nilai sangatlah baik ditanamkan sejak dini sebagai pencegahan konflik nilai akibat berbedaan identitas, gender, etnis, ras, dan kultur. Oleh sebab itu, pendidikan nilai melalui pembelajaran berbasis multikultural harus makin digencarkan dan sebagai subjek utamanya adalah siswa sekolah dasar. Dengan ini diharapkan mereka siap bidup dalam keberbedaan secara damai dan harmonis.
\end{abstract}

Kata kunci: Pendidikan nilai, multikultural, sekolah dasar 


\section{Pendahuluan}

Pendidikan adalah pengembangan berbagai potensi manusiawi agar hidupnya dapat sejalan dengan fitrah dan sunnatullah. Salah satu fungsi pendidikan adalah fungsi sosial, yaitu mengenalkan dan mengkondisikan murid-murid untuk menerima dan siap hidup dalam keberbedaan secara damai dan harmoni. ${ }^{1}$ Dengan demikian, menghadapi beragam kultur di sekolah maka pendidikan multikultur sangat perlu diterapkan.

Pendidikan multikultural didefinisikan sebagai pendidikan untuk keragaman budaya dalam merespon perubahan demografis dan kultural lingkungan kehidupan masyarakat tertentu bahkan dunia secara menyeluruh. Hal ini tedak akan lepas dari makna nilai. Nilai-nilai hendaknya terjadi dalam keseluruhan proses pembelajaran di kelas, dalam ekstrakulikuler, dalam bimbingan dan penyuluhan, dan upacara pemberian penghargaan, dan semua aspek kehidupan. Bagi bangsa Indonesia sendiri, terdapat sebuah program. Program tersebut dikenal dengan Iiving value education. Ini dipersembahkan sebagai sebuah program pendidikan dengan pelatihan dan metodologi praktis bagi siswa, fasilitator, pekerja sosial, orang tua dan pendamping anak untuk membantu mereka menggali serta mengembangkan nilai-nilai universal. Mengasosiasi nilai tersebut dalam keterampilan sosial-emosional dan intrapersonal-interpersonal mereka sehari-hari.

Pendidikan multikultural dapat menjadi salah satu metode efektif meredam konflik. Lebih dari itu, pendidikan multikultural dapat menanamkan sekaligus mengubah pemikiran peserta didik untuk tulus menghargai etnik, agama, ras, dan antargolongan. Sekolah yang baik adalah sekolah yang belajar, bukan tempat bagi siswa belajar akan tetapi juga untuk berkembang. Mengakui ketepatan pandangan-pandangan budaya yang beragam, membantu siswa dalam mengembangkan kebanggaan terhadap warisan

1 Rohmat Mulyana, Mengartikulasikan Pendidikan Nilai, (Bandung: Alfabeta, 2011), hlm. 269. budaya mereka, menyadarkan kepada siswa bahwa konflik nilai sering menjadi penyebab konflik antar kelompok masyarakat. Pembelajaran multikultural diselenggarakan dalam upaya membantu siswa dalam mengembangkan kemampuan siswa dalam memandang kehidupan dari berbagai perspektif budaya yang berbeda dengan budaya yang mereka miliki, dan bersikap positif terhadap perbedaan

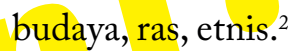

Berkaitan dengan konflik nilai yang mencuat saat ini, maka program menghidupkan nilai melalui pembelajaran berbasis multikultural di sekolah harus lebih digencarkan. Oleh sebab itu penulis mencoba menganalisa bagaimana konsep dan perkembangan pembelajaran multikultural dan kaitannya dengan program pendidikan menghidupkan nilai di Indonesia dan dunia secara luas.

\section{Pembahasan}

\section{Living Values Education}

Pada dasarnya, pendidikan nilai dirumuskan dari dua pengertian dasar yang terkandung dalam istilah pendidikan dan istilah nilai. Ketika arti pendidikan dan arti nilai dimaknai berbeda, definisi pendidikan nilai pun beragam, tergantung pada tekanan dan rumusan yang diberikan kepada kedua istilah itu. Seperti dikemukakan oleh Sastrapratedja, pendidikan nilai adalah penanaman dan pengembangan nilai-nilai pada diri seseorang. Pengertian yang hampir sama oleh Mardiatmadja mendefinisikan pendidikan nilai sebagai bantuan terhadap peserta didik agar menyadari dan mengalami nilai-nilai serta menempatkannya secara integral dalam keseluruhan hidupnya. ${ }^{3}$

Menurut Diane Tillman Living Values Educational Program merupakan program pendidikan nilai-nilai. Program ini menyajikan

2 Farris, P.J. \& Cooper, SM. Elementary Social Studies: a whole language Approach. (Iowa: Brown \& Bencmark Publisher, 1994), hlm. 23.

3 Rohmat Mulyana, Mengartikulasikan Pendidikan Nilai, hlm.118-119. 
berbagai macam aktivitas pengalaman dan metodologi praktis bagi para guru untuk membantu murid-murid mengeksplorasi dan mengembangkan nilai-nilai kunci pribadi dan sosial: kedamaian, penghargaan, cinta, tanggung jawab, kebahagiaan, kerjasama, kejujuran, kerendahan hati, toleransi, kesederhanaan, dan persatuan. Terdapat pula segmen khusus untuk para orang tua, pengasuh, juga bagi para pengungsi dan anak-anak korban perang. ${ }^{4}$

LVEP adalah kegiatan nilai dan pengembangan karakter yang secara menyeluruh mendasari hubungan harmonis antara manusia dengan manusia, manusia dengan alam dan lingkungannya. LVEP percaya bahwa orang dewasa adalah panutan yang penting dalam menghidupkan nilai-nilai, dan program ini bekerja pada tingkat sekolah dan komunitas. Mendorong perencanaan pengembangan sekolah untuk mengenali nilai yang dijunjung bersama. Kepercayaan bersama menjadi inti dari sistem pendidikan, dan akan menggerakkan perwujudan visi dan misi sekolah. Kurikulum LVEP mencakup 12 unit aktivitas bermuatan nilai-nilai: kedamaian, penghargaan, kasih sayang, toleransi, kejujuran, kerendahan hati, kerjasama, kebahagiaan, tanggung jawab, kesederhanaan, kebebasan dan persatuan. $^{5}$

Dalam praktiknya, pendidikan nilai hendaknya terjadi dalam keseluruhan proses pembelajaran di kelas, dalam ekstrakulikuler, dalam bimbingan dan penyuluhan, dan upacara pemberian penghargaan, dan semua aspek kehidupan. Beberapa contoh mengenai ini misalnya kegiatan belajar kelompok, penggunaan bahan bacaan dan topik penulisan mengenai "kebaikan", penggunaan strategi klarifikasi nilai dan dilema moral, pemberian teladan

4 Darmiyati Dzuchdi, Model Pendidikan Karakter: Integrasi dalam Pembelajaran dan Pengembangan Kultur Sekolah, (Yogyakarta: UNY Press, 2012), hlm. 76.

5 Budhy Munawar Rachman \& Para Trainer Living Values Education (LVE), Pendidikan Karakter: Pendidikan Menghidupkan Nilai untuk Pesantren, Madrasah, dan Sekolah, (The Asia Foundation, 2017), hlm. xviii. "tidak merokok", "dermawan", "menyayangi sesama makhluk Allah", dan sebagainya. ${ }^{6}$

Bagi bangsa indonesia sendiri, Iiving value education dipersembahkan sebagai sebuah program pendidikan dengan pelatihan dan metodologi praktis bagi siswa, fasilitator, pekerja sosial, orang tua dan pendamping anak untuk membantu mereka menggali serta mengembangkan nilainilai universal. Mengasosiasi nilai tersebut dalam keterampilan sosial-emosional dan intrapersonalinterpersonal mereka sehari-hari. ${ }^{7}$

Akhirnya, dapat dipahami bahwa pengembangan nilai-nilai karkter tersebut mampu menjadi bekal bagi setiap individu untuk hidup bersama dalam berbagai ragam ilmu, sosial, budaya. Dengan kata lain, di lingkungan sekolah khususnya sekolah dasar yang berperan penting sebagai orang dewasa adalah para pendidik. Mereka seharusnya menjiwai dan menghayati profesi peran untuk menghidupkan muatan nilai-nilai kedamaian, persatuan, kerjasama, kesederhanaan dan nilai lainnya kepada para perserta didik melalui pembelajaran sehingga cita-cita untuk hidup harmonis dalam wilayah multikultur dapat tercapai dengan baik.

\section{Landasan Pendidikan Nilai}

Pertama, landasan psikologis. Kekhasan Psikologi dalam menelaah manusia terletak pada pandangannya bahwa manusia sebagai individu selalu tampil unik. Psikologi untuk menarik batas-batas kemiripan melalui kaidahkaidah perkembangan mental manusia beserta ciri-ciri perilakunya. Keutuhan manusia sebagai organisme dijelaskan melalui aspek-aspek psikis yang berkembang secara dinamis. Demikian pula perbedaan individu ditarik pada prinsip-prinsip dasar perkembangan yang mewakili setiap fase pertumbuhan dan perkembangan manusia.

6 Ibid., hlm.11.

7 Internasional Seminar on Character Education: Living Values Education Approach, at UIN Yogyakarta, November $21^{\text {st }}, 2016$. 
Aspek pendidikan nilai yang dapat dijelaskan antara lain adalah motivasi, dan perbedaan individu. Motivasi menjadi aspek penting yang perlu dikembangkan. Dari sejumlah kajian tentang motivasi menunjukkan bahwa dorongan-dorongan psikologis manusia bergerak secara dinamis dalam suatu kontinum yang menempatkan nilai pada ujung pertimbangan psikologis. Pendidikan nilai harus mampu membangkitkan motivasi peserta didik ke arah yang didasarkan pada pilihan kebenaran, kebaikan, dan keindahan. ${ }^{8}$ Dengan demikian, motivasi harusnya senantiasa ditanamkan pada diri peserta didik agar bertahan sepanjang hayat.

Selanjutnya adalah perbedaan individu. Perbedaan individubaik perkembangan fidik maupun mental dapat menjadi kekuatan atau kelemahan pada dirinya. Misalnya, ada siswa yang cerdas, rajin, tekun, shaleh, atau gemuk ataupun sebaliknya. Dalam mengajarkan dan membimbing peserta didik ke arah pilihan nilai kehidupan yang tepat, fungsional, kontekstual, serta sesuai dengan kebutuhan hidup mereka. Dengan kata lain dapat mengajarkan secara adil, paham materi dan metodenya. ${ }^{9}$ Oleh sebab itu untuk mengatasi kompleksitas perbedaan individu dalam belajar nilai, pendidik sebaiknya menggali dari berbagai sumber. Selain itu pendidik perlu melalui proses penyadaran dan pengenalan nilai. Hal ini disesuaikan dengan tahapan perkembangan minat dan kepedulian anak terhadap nilai.

Kedua, landasan sosial. Manusia adalah makhluk sosial. Target utama pendidikan nilai secara sosial adalah membangun kesadarankesadaran interpersonal yang mendalam. Peserta didik dibimbing untuk mampu menjalin hubungan sosial secara harmonis dengan orang lain melalui sikap dan perilaku yang baik. Ia dilatih untuk berprasangka baik kepada orang lain, berempati, suka menolong, jujur, bertanggung jawab, dan menghargai perbedaan pendapat. Semua sikap itu dapat membantu peserta didik untuk hidup secara sehat dan harmonis dalam lingkungan sosial yang dihuninya.

Ketiga, landasan estetik. Manusia adalah makhluk yang memiliki keindahan. Cita rasa keindahan (estetik) berkembang sesuai dengan potensi secara individu dalam menilai objekobjek yang bernilai seni atau menuangkan karya seni. Pada tingkatan tertentu, cita rasa keindahan berkembang secara subjektif, dalam arti setiap orang dapat mengekspresikan kualitas dan intensitas keindahan yang berbeda. Namun dalam tingkatan yang lebih tinggi, cita rasa keindahan dapat sampai pada penemuan makna keindahan yang hakiki, sehingga ia berada pada wilayah yang objektif. Yakni kebenaran dan kebaikan estetik yang bernilai universal. ${ }^{10}$

\section{Landasan Kultural pendidikan Nilai}

Dalam konteks pendidikan nasional, pendidikan nilai perlu diartikulasikan sesuai dengan nilai-nilai luhur bangsa yang bersifat kultural dan spiritual. Landasan-landasan umum yang sebelumnya sudah dijelaskan sebagai bagian bari pemberian makna tentang penyadaran nilai yangmengacu pada landasan yuridis dan religi yang berkembang dalam masyarakat kita.

Penyelenggaraan pendidikan nilai dalam konteks pendidikan nasional sebenarnya memiliki landasan hukum yang kuat. Di antaranya Ideologi negara, undang-undang, dan GBHN merupakan ketentuan yuridis yang mengandung banyak pesan nilai. Karena itu, pendidikan nilai memiliki posisi yang strategis dalam pendidikan nasional.

Selanjutnya adalah landasan religi. Bangsa Indonesia adalah bangsa yang beragama. Setiap pribadi bangsa memiliki keyakinan bahwa nilai ketuhanan adalah nilai tertinggi. Perwujudan atas keyakinan yang dianut dicerminkan dalam beragam

\footnotetext{
8 Rohmat Mulyana, hlm. 127.

9 Ibid., 129.
}

${ }^{10}$ Ibid., 133-134.. 
bentuk ritualitas peribadatan yang dilakukan oleh setiap komunitas beragam. ${ }^{11}$

\section{Pembelajaran Multikultural}

Mutikulturalisme adalah kebudayaan. Secara istilah multikulturalisme dibentuk dari kata multi (banyak), dan kultur (budaya), dan isme (aliran). Hakikatnya, kata terkandung pengakuan akan martabat manusia yang hidup dalam komunitasnya dengan kebudayaan masing-msing yang unik. Dengan demikian setiap individu akan merasa dihargai dalan hidup bersama dan memiliki tanggung jawab. ${ }^{12}$

Ada banyak definisi tentang pendidikan multikultural. Menurut Kuper, pendidikan Multibudaya dalam Ensiklopedi Ilmu-ilmu Sosial dimulai sebagai gerakan reformasi pendidikan di Amerika serikat selama perjuangan hak-hak kaum sipil Amerika keturunan Afrika pada tahun 1960-an dan 1970-an. Perubahan kemasyarakatan yang mendasar seperti integrasi sekolah-sekolah negeri dan peningkatan populasi imigran telah memberikan dampak yang besar atas lembagalembaga pendidikan. ${ }^{13}$

James Banks and Cherry McGee Banks (2004) mendefinisikan pendidikan multikultural adalah " $a$ field of study designed to increase educational equity for all student". Untuk memperluas definisinya, James Banks mengembangkan lima dimensi dari pendidikan multikultural, di antaranya sebagai berikut. ${ }^{14}$

1) Content integration

2) Knowledge construction process

${ }^{11}$ Ibid., 153.

${ }^{12}$ Mahfud, Choirul, Pendidikan Multikultural, (Yogyakarta: Pustaka Pelajar, 2006), hlm. 75.

${ }_{13}$ Adam Kuper \& Jessica Kuper, Ensiklopedi Ilmu-Ilmu Sosial, (Jakarta: Raja Grafindo, 2000), hlm. 10.

${ }^{14}$ Souto-Manning, Mariana, Multicultural Teaching in the Early Childhood Classroom: approaches, strategies, and tools, preschool-2nd grade, (Amsterdam: Teacher College Press, 2013), hlm. 3-4.
3) Prejudice reduction

4) Equity pedagogy

5) Empowerment of school culture and social structure

Berdasarkan hal ini dapat diasumsikan bahwa multikultural merupakan studi yang didesain untuk meningkatkan ekuitas pendidikan bagi peserta didik. dalam pengembangan terdapat integrasi konten/ materi, proses konstruksi pengetahuan, reduksi prasangka, pendidikan ekuitas, dan penguasaan/ pemberdayaan kultur sekolah dan struktur sosial.

Dalam dimensi integrasi materi ini digunakan untuk memberikan keterangan dengan poin kunci pembelajaran dengan merefleksi materi yang berbeda-beda. Pada dimensi kontruksi pengetahuan para pendidik membantu peserta didik untuk memahami dan merumuskan kesimpulan yang dipengaruhi oleh disiplin pengetahuan yang mereka miliki. Selanjutnya guru melakukan banyak usaha untuk mengembangkan perilaku positif tentang perbedaan kelompok. Pada dimensi pengurangan prasangka ini pembelajaran memiliki cita positif. Selanjutnya adalah dimensi pendidikan yang sama atau adil. Ini dirancang untuk membentuk lingkungan sekolah, memperhatikan caracara mengubah fasilitas pembelajaran sehingga mempermudah pencapaian hasil belajar. Dimensi yang terakhir dimaksudkan untuk pemberdayaan budaya sekolah dan struktur sosial.

Pendidikan multikultural didefinisikan sebagai pendidikan untuk keragaman budaya dalam merespon perubahan demografis dan kultural lingkungan masyarakat tertentu bahkan dunia secara menyeluruh. Sebagaimana pendapat Paulo Freire dalam buku Politik Pendidikan, pendidikan bukan merupakan menara gading yang berusaha menjauhi realitas sosial dan budaya. Pendidikan harus mampu menciptakan tatanan masyarakat yang hanya mengagungkan prestise sosial sebagai akibat kekayaan dan kemakmuran yang dialaminya. 
Pendidikan multikultural merupakan suatu pendekatan progressive untuk melakukan transformasi pendidikan yang menyeluruh membongkar kekurangan dan kegagalan, dan praktik-praktik diskriminasi dalam proses pendidikan. Selain daripada itu, Musa Asy'arie menyatakan bahwa pendidikan multikultural merupakan proses penanaman cara hidup menghormati, tulus, dan toleran terhadap keragaman budaya yang hidup di tengah-tengah masyarakat plural. Dengan demikian diharapkan adanya kekenyalan dan kelenturan mental bangsa menghadapi benturan konflik sosial. ${ }^{15}$ Dengan demikian, pendidikan multikultur menjadi tombak peredam dan upaya pencegahan munculnya konflik.

Pembelajaran multikultural adalah kebijakan dalam praktik pendidikan dalam mengakui, menerima dan menegaskan perbedaan dan persamaan manusia yang dikaitkan dengan gender, ras, dan kelas (Seeter and Grant, 1998). Pembelajaran berbasis multikultural didasarkan pada gagasan filosofis tentang kebebasan keadilan, kesederajatan dan perlindungan terhadap hak-hak manusia. Hakikat pendidikan multikultural mempersiapkan seluruh siswa untuk bekerja secara aktif menuju kesamaan struktur dalam organisasi dan lembaga sekolah. Ini Kebijakanlah kebijakan yang mengarah pada pelembagaan inklusif dan pengajaran inklusif dan pengajaran oleh propaganda pluralisme lewat kurikulum yang berperan bagi kompetensi budaya individual.

Pembelajaran berbasis multikultural berusaha memberdayakan siswa untuk mengembangkan rasa hormat kepada orang yang berbeda budaya, memberi kesempatan untuk bekerja bersama dengan orang atau kelompok orang yang berbeda etnis atau rasnya secara langsung. Ini membantu siswa untuk mengakui ketepatan dari pandanganpandangan budaya mereka, menyadarkan siswa dalam mengembangkan kebanggaan terhadap

${ }_{15}$ Musa Asy'arie, "Pendidikan multikultural dan konflik bangsa”, www.kompas.co.id. Diakses pada 20 Februari 2017. warisan budaya mereka, menyadarkan siswa bahwa konflik nilai sering menjadi penyebab konflik antar kelompok masyarakat (Savage \& Amstrong). Dengan demikian dapat disimpulkan bahwa pembelajaran berbasis multikultural sangat bersinergi dengan pembangunan bangsa yang berkarakter.

Berkaitan dengan karakter bangsa dan implementasi nilai karakter dalam pembelajaran, terdapat nilai-nilai karakter yang bisa diintegrasikan dalam pembelajaran siswa. Tentang beberapa contoh nilai karakter yang dapat diintegrasikan, Albantani dan Madkur menyatakan bahwa, "there are four character that can be integrated in learning; those are polite, appreciative, creative, and communicative. Whereas in the implementation, the character appreciates the others which are taught in he phase of whilst-activity, while the teachers contain one other character that is social care which is also implemented in the phase of pre-release activity. "16 Penanaman nilai sudah digaungkan sejak konsep pendidikan karakter menjadi salah satu fokus penekanan dalam kurikulum 2013.

Dalam proses pembelajaran, karakter-karakter tersebut tentunya sangat sesuai dengan pembelajaran berbasis multikultur. Peserta didik kelas dasar diharapkan memulai dan mampu beradaptasi dengan keadaan lingkungan sekitar. Sebagaimana yang telah dijelaskan bahwa pembelajaran multikultural diselenggarakan dalam upaya membantu siswa dalam mengembangkan kemampuan siswa dalam memandang kehidupan dari berbagai perspektif budaya yang berbeda dengan budaya yang mereka miliki, dan bersikap positif terhadap perbedaan budaya, ras, etnis. Selain itu menambah pemahaman kepada pengajar maupun peserta

${ }^{16}$ Azkia Muharom Albantani \& Ahmad Madkur, "Integrating Character Education Values In Language Teaching: Why and How," International Conference 2016. hlm. 08. dalam https://www.researchgate.net/publication/309556734_ INTEGRATING_CHARACTER_EDUCATION_ VALUES_IN_LANGUAGE_TEACHING_WHY_AND_ HOW , diakses 27 Februari 2017. 
didik akan perlunya pengertian dan wawasan akan kebudayaan tempat berada. Pembelajaran berbasis multikultural akan memberikan suatu pelajaran tentang budaya pada tempat yang bersangkutan serta mampu menciptakan lingkungan pendidikan yang berwawasan nasional tanpa meninggalkan karakter lokal.

Farris \& Banks dalam karya ilmiah Syahid, terdapat beberapa identifikasi tujuan-tujuan pembelajaran berbasis multikultur, di antarannya: (1) memfungsikan perana sekolah dalam memandang keberadaan siswa yang beranekaragam; (2) membantu siswa dalam membangun perlakuan yang positif terhadap perbedaan kultural, ras, etnik, kelompok keagamaan; (3) memberikan ketahanan siswa dengan cara mengajar mereka dalam mengambil keputusan dan keterampilan budaya; (4) membantu siswa dalam membangun ketergantungan lintas budaya dan memberi gambaran positif kepada mereka mengenai perbedaan kelompok; (5) membantu siswa memiliki pengetahuan, sikap, keterampilan untuk berpartisipasi di dalam demokrasi dan kebebasan masyarakat; (6) memajukan kebebasan, kecakapan, keterampilan, terhadap lintas batas-batas etnik dan budaya untuk berpartisipasi dalam beberapa kelompok dan budaya orang lain. ${ }^{17}$

Adapun cara untuk mencapai tujuan-tujuan tersebut adalah dengan memasukkan nilai-nilai multikultur dalam pembelajaran. Yang pertama yang dapat dilakukan oleh pendidik khususnya di sekolah dasar adalah mengenalkan kepada peserta didik tentang pluralisme budaya yang ada di luar dirinya. Setelah mereka mengenal budaya di luar dirinya, kemudian guru harus mendorong untuk mengembangkan sikap peserta didik agar mau dan mampu menghargai budaya yang ada di luar dirinya dan pasti memiliki perbedaan. Dalam prosesnya,

${ }^{17}$ Ahmad Syahid, "Aplikasi Pembelajaran Berwawasan Multikultural Di Sekolah Dasar Muhammadiyah 3 Palu," (Istiqra: Jurnal Penelitian Ilmiah, Vol. 1, No.1 Januari-Juni 2013. hlm.111. dalam www.jurnal.iainpalu.ac.id Diakses pada 20 Februari 2017. guru harus menggunakan metode yang tepat untuk perkembangan anak usia dasar atau jenjang sekolah dasar.

\section{Pengembangan Pendidikan Nilai Berbasis Multikultural}

Pendidikan nilai yang berbasis multikultural dilakukan dan disampaikan pada pokok bahasan yang diajarkan dan karena sifatnya dapat tersurat atau tersembunyi maka menuntut guru untuk dapat merancang atau melihat peluang nilai karakter itu dapat dipadukan dalam sistem pembelajaran. Pembelajaran nilai yang dapat dilakukan dengan memberikan pemahaman tentang makna akhlak yang baik, interaksi, saling menghargai dan menghormati, menolong, melaksanakan aturan, menghargai kebersamaan dan perbedaan. ${ }^{18}$

Adapun rancangan pembelajaran berbasis multikultural adalah sebagai berikut: ${ }^{19}$

a. Mengembangkan pembelajaran multikultural yang inovatif dengan karakteristik: student centered approach, contextual learning, multi model dan metode, strategi, multi media, multi sumber belajar, multi evaluasi yang mencakup pengetahuan, keterampilan, dan sikap

b. Pengembangan model pembelajaran berbasis multikultural, meliputi: merumuskan kompetensi pembelajaran multikultural bagi subjek belajar meliputi knowledge, skills, disposition; menetapkan posisi guru sebagai director of learning; analisis terhadap latar kondisi siswa yang multikultural; mengembangkan materi pelajaran yang bernuansa multikultural

${ }^{18}$ Hadi Mahmud, "Pendidikan Nilai Karakter Berbasis Multikultural," dalam www.ejournal.iainkendari.ac.id Diakses pada 24 Februari 2017.

${ }^{19}$ Leurencia Primawati, "Pembelajaran Multikultural melalui Pendidikan Multikultural Berbasis Nilai Kebangsaan,” JUPIIS Vol 5 No.2 Desember 2013, dalam www.portalgaruda. org, diakses pada 24 Februari 2017. 
melalui analisis materi yang relevan dengan pembelajaran berbasis multikultural.

c. Menyusun rancangan pembelajaran berbasis multikultural melalui empat tahapan utama, yakni: analisis isi (content analysis), analisis latar kultural (setting analysis), pengorganisasian materi (content organizing), dan menyusun format model pembelajaran berbasis multikultural.

Selanjutnya, berkaitan dengan rencana-rencana tersebut, semoga dapat diaktualisasikan secara optimal dalam kehidupan riil di sekolah. Pendidikan multikultural di kelas dan di sekolah berorientasi pada nilai-nilai keadaban dan berdasar pada nilai ketuhanan, kemanusiaan, kebangsaan, kerakyatan, dan keadilan. Dan pada akhirnya memberikan alternatif terhadap permasalahan multikultural dalam menjaga integrasi dan keharmonisan.

Secara konseptual pendidikan nilai dan pembelajaran multikultural merupakan bagian yang tak terpisahkan dari proses pendidikan secara menyeluruh. Pendidikan nilai secara subtantif melekat pada semua dimensi tujuan tersebut yang memusatkan perhatian pada nilai keagamaan dan nilai sosial, nilai keilmuan, dan nilai demokratis yang bertanggung jawab. Pendidikan nilai menggambarkan bahwa nilai tidak semata-mata ditangkap dan diajarkan, namun nilai lebih jauh, nilai dicerna, diinternalisasikan, dan dilekatkan dalam kualitas pribadi melalui proses belajar yang berada dalam masyarakat berkebudayaan. Oleh sebab itu, proses pendidikan, pembelajaran pada dasarnya adalah proses pembudayaan untuk mencetak manusia yang beradab.

\section{Penutup}

Kultur kehidupan negeri ini begitu kompleks. Indikator untuk hidup bersama dalam keberagaman adalah mampu hidup harmonis. Semua itu tidak terlepas dari nilai. Nilai tersebut adalah nilai keagamaan, nilai sosial, nilai keilmuan dan lain sebagainya. Pendidikan tidak akan lepas dari nilainilai kehidupan. Maka dari itu, sebagai upaya meredam konflik yang mencuat dan pencegahan munculnya konflik akibat kebragaman adalah dengan mengaplikasikan pembelajaran berbasis multikultural, menghidupkan nilai-nilai pendidikan. Upaya pencegahan ini dilakukan sejak usia dini lebih-lebih saat berada di sekolah dasar. Dengan ini diharapkan siswa sekolah mampu menyadari akan perbedaan budaya, pandangan dan sebagainya, sekolah yang baik adalah sekolah sebagai tempat belajar dan berkembang dengan baik, mampu mengahsilkan anak bangsa yang menghargai dan menghormati keberbedaan, berinteraksi dan berkembang dalam kehidupan masyarakat, bangsa, dan negara yang multikultur.

\section{Referensi}

Albantani, Azkia Muharom \& Madkur, A. "Integrating Character Education Values In Language Teaching: Why and How," Makalah pada the $4^{\text {th }}$ ELITE Conference 2016, diakses dari https://www.researchgate.net/project/The4th-ELITE-CONFERENCE-UIN-JAKARTA pada tanggal 27 Februari 2017.

Farris, P.J. \& Cooper, SM.Elementary Social Studies: a whole language Approach. (Iowa: Brown \& Bencmark Publisher, 1994.

Grant, Carl A. \& Lei, Joy L., Global Constructions of Multicultural Education: Theories and Realities, London: LEA Lawrence Erlbaum Associated, 2001.

Lickona, Thomas, "Pendidikan Karakter :Penduan Lengkap Mendidik siswa Menjadi Pintar dan Baik" Terj. Educating for Character. New York: Bantam Book, 2008.

Mahfud, Choirul, Pendidikan Multikultural, Yogyakarta: Pustaka Pelajar, 2006. 
Mahmud, Hadi, "Pendidikan Nilai Karakter Berbasis Multikultural," dalam www.ejournal. iainkendari.ac.id, diakses pada 24 Februari 2017.

Mulyana, Rohmat, Mengartikulasikan Pendidikan Nilai, Bandung: Alfabeta, 2011.

Rachman, Budhy Munawar \& Para Trainer Living Values Education (LVE), Pendidikan Karakter: Pendidikan Menghidupkan Nilai untuk Pesantren, Madrasah, dan Sekolah, The Asia Foundation, 2017.

Souto-Manning, Mariana, Multicultural Teaching in the Early Childhood Classroom: approaches, strategies, and tools, preschool-2nd grade, Amsterdam: Teacher College Press, 2013.
Syahid, Ahmad, "Aplikasi Pembelajaran Berwawasan Multikultural Di Sekolah Dasar Muhammadiyah 3 Palu," (Istiqra: Jurnal Penelitian Ilmiah, Vol. 1, No.1 Januari-Juni 2013. hlm.111. dalam www.jurnal.iainpalu.ac.id, diakses pada 20 Februari 2017.

Wiyono, Teguh, "Implementasi Pendidikan Multikultural dalam Praksis Pendidikan di Indonesia," dalam www.pendidikan-diy.go.id, dipublish 29 Oktober 2014, diakses Senin 20 Februari 2017.

Zuchdi, Darmiyati, Model Pendidikan Karakter: Integrasi dalam Pembelajaran dan Pengembangan Kultur Sekolah, Yogyakarta: UNY Press, 2012 